\title{
Effect of Penetration Enhancers on Toenail Delivery of Efinaconazole from Hydroalcoholic Preparations
}

\author{
Jun Soo Park ${ }^{1, \dagger}$, Jeong Soo Kim ${ }^{2,+}$, Myoung Jin Ho ${ }^{1}$, Dong Woo Park ${ }^{1}$, Eun A. Kim ${ }^{1}$, Yong Seok Choi ${ }^{1}$, \\ Sun Woo Jang ${ }^{2}$ and Myung Joo Kang ${ }^{1, *}$ \\ 1 Colledge of Pharmacy, Dankook University, Dongnam-gu, Cheonan 330-714, Chungnam, Korea; \\ chon523273@gmail.com (J.S.P.); butable@gmail.com (M.J.H.); eastkingdw@hanmail.net (D.W.P.); \\ anemone014@naver.com (E.A.K.); analysc@dankook.ac.kr (Y.S.C.) \\ 2 Dong-A Pharmaceutical Co. Ltd., Giheung-gu, Yongin 446-905, Gyeonggi, Korea; js_kim@donga.co.kr (J.S.K.); \\ chb@donga.co.kr (S.W.J.) \\ * Correspondence: kangmj@dankook.ac.kr; Tel.: +82-41-550-1446 \\ + These authors contributed equally to this work.
}

Citation: Park, J.S.; Kim, J.S.; Ho, M.J.; Park, D.W.; Kim, E.A.; Choi, Y.S.; Jang, S.W.; Kang, M.J. Effect of Penetration Enhancers on Toenail Delivery of Efinaconazole from Hydroalcoholic Preparations. Molecules 2021, 26, 1650. https:// doi.org/10.3390/molecules26061650

Academic Editor: Luigi A. Agrofoglio

Received: 17 December 2020

Accepted: 9 March 2021

Published: 16 March 2021

Publisher's Note: MDPI stays neutral with regard to jurisdictional claims in published maps and institutional affiliations.

Copyright: (c) 2021 by the authors. Licensee MDPI, Basel, Switzerland. This article is an open access article distributed under the terms and conditions of the Creative Commons Attribution (CC BY) license (https:// creativecommons.org/licenses/by/ $4.0 /)$.

\begin{abstract}
The incorporation of permeation enhancers in topical preparations has been recognized as a simple and valuable approach to improve the penetration of antifungal agents into toenails. In this study, to improve the toenail delivery of efinaconazole (EFN), a triazole derivative for onychomycosis treatment, topical solutions containing different penetration enhancers were designed, and the permeation profiles were evaluated using bovine hoof models. In an in vitro permeation study in a Franz diffusion cell, hydroalcoholic solutions (HSs) containing lipophilic enhancers, particularly prepared with propylene glycol dicaprylocaprate (Labrafac PG), had 41\% higher penetration than the HS base. Moreover, the combination of hydroxypropyl- $\beta$-cyclodextrin with Labrafac PG further facilitated the penetration of EFN across the hoof membrane. In addition, this novel topical solution prepared with both lipophilic and hydrophilic enhancers was physicochemically stable, with no drug degradation under ambient conditions $\left(25^{\circ} \mathrm{C}\right.$, for 10 months). Therefore, this HS system can be a promising tool for enhancing the toenail permeability and therapeutic efficacy of EFN.
\end{abstract}

Keywords: efinaconazole; transungual drug delivery; hydroalcoholic solution; permeation enhancer; bovine hoof; onychomycosis; propylene glycol dicaprylocaprate; hydroxypropyl- $\beta$-cyclodextrin

\section{Introduction}

Onychomycosis is one of the most chronic and prevalent nail disorders, caused by fungal infection. Epidemiological studies suggest about $19 \%$ of the global population is affected by onychomycosis caused by dermatophytes (Trichophyton rubrum and Trichophyton mentagrophytes), non-dermatophyte molds, and yeasts (Candida albicans) [1,2]. Efinaconazole (EFN, Figure 1), the first topical triazole derivative, is prescribed for the treatment of toenail onychomycosis. This antifungal agent has been demonstrated to be potent against Trichophyton rubrum, Trichophyton mentagrophytes, and Candida albicans in toenail by obstructing ergosterol biosynthesis, presumably through sterol 14-demethylase inhibition $[3,4]$. Topical application of EFN solution $(10 \% \mathrm{w} / \mathrm{w})$ was markedly efficacious than other topical treatments with amorolfine or ciclopirox against mild to moderate subungual onychomycosis [5]. Currently, the marketed product of EFN is designed as a hydroalcoholic topical solution (Jublia, Kaken Pharmaceutical Co., Ltd. (Tokyo, Japan)) [6]; ethanol is employed as a volatile vehicle to dissolve the antifungal agent. In addition, to enhance the skin and/or nail delivery of EFN, lipophilic enhancers, such as myristyl lactate and diisopropyl adipate, are included, along with cyclomethicone as a wetting agent. Upon topical application, the organic vehicle is rapidly vaporized, providing high drug concentration onto the nail plate. Subsequently, EFN molecules diffuse through the nail plate with lipophilic permeation enhancers. 
<smiles>C=C1CCN(C(C)C(Cn2cncn2)c2ccc(F)cc2F)CC1</smiles>

Figure 1. Chemical structure of efinaconazole.

In designing topical preparations of antifungal agents, especially for toenail treatment, endowing satisfactory penetration into the relevant layer, including the nail plate, is one of the pivotal factors influencing therapeutic efficacy [7-9]. The nail plate is a thin $(0.25-1.00 \mathrm{~mm})$, hard, and convex-shaped structure, which is principally made of fibrous proteins, approximately 80-90 layers of keratinized cells, and keratin filaments $[10,11]$. These components are tightly junctioned via a disulfide link which is responsible for the toughness and barrier function of nails. Most antifungal agents are lipophilic and possess high affinity for keratinized tissues, including the toenail, which can have a deleterious effect on drug absorption, impeding drug penetration to deeper layers of the nail plate [12]. Although EFN has a relatively lower binding affinity to keratinized tissue compared to several lipophilic antifungal agents [5], topical preparation possessing an enhanced penetration profile is still required to improve the therapeutic efficacy of the triazole derivative in patients with onychomycosis. Actually, the increased topical delivery of EFN markedly accelerated the structural recovery of keratin layer in a guinea pig onychomycosis model [13].

To enhance the ungual delivery of antifungal agents, different strategies have been utilized, such as chemical modification of antifungal agents, employment of penetration enhancers, nanocarrier-based delivery, and mechanical or physical approaches, including iontophoresis, photodynamic therapy, and lasers $[11,14,15]$. The incorporation of permeation enhancers in topical preparations, such as lacquer, cream, or hydrogel, have been widely explored to increase drug penetration into the toenail, as a simple and effective technique $[8,13]$. Saner et al. (2014) reported that topical treatment with lipophilic excipients principally altered the microstructure of the nail plate through physical interaction with the lipid components of the plate, promoting drug penetration [16]. On the other hand, hydrophilic enhancers, such as polyethylene glycols, pantothenic acid, hydroxypropyl- $\beta$ cyclodextrin (HP- $\beta-C D$ ) or sodium lauryl sulfate (SLS) has been shown to increase drug penetration across the nail plate by improving the hydration level of the nail plate, forming a porous microchannel, or by decreasing the contact angle between topical solution and the surface or nail plaque [17-20]. As the aforementioned chemical approach relies on the chemical structure and physicochemical nature of therapeutic agents, a case-specific formulation study is essential to find the finest composition.

The objective of the present study was to design a topical preparation for EFN with high ungual permeation profile. Different hydroalcoholic solutions (HSs) containing several lipophilic enhancers (L-HSs, Table 1) were formulated, and their physicochemical properties and permeation profile through the bovine hooves were evaluated. After selecting a lipophilic enhancer, HSs containing both lipophilic and hydrophilic permeation enhancers (LH-HSs, Table 2) were further designed, and their permeation profiles were evaluated with L-HSs including formula similar to the marketed product (L-HS1), or several oil solutions (OSs, Table 3). The physicochemical stability of the optimized topical formula was assessed under stress and ambient conditions. 
Table 1. Compositions and physicochemical characteristics of efinaconazole (EFN)-loaded hydroalcoholic solutions (HSs) with different lipophilic permeation enhancers.

\begin{tabular}{|c|c|c|c|c|c|c|c|}
\hline & HS base & L-HS1 & L-HS2 & L-HS3 & L-HS4 & L-HS5 & L-HS6 \\
\hline \multicolumn{8}{|l|}{ Compositions } \\
\hline EFN $(g)$ & 1.0 & 1.0 & 1.0 & 1.0 & 1.0 & 1.0 & 1.0 \\
\hline Myristyl lactate (g) & - & 1.0 & - & - & - & - & - \\
\hline Lauroglycol $90(\mathrm{~g})^{(1)}$ & - & - & 2.2 & - & - & - & - \\
\hline Labrafac PG (g) (2) & - & - & - & 2.2 & - & - & - \\
\hline Medium-chain triglyceride (g) & - & - & - & - & 2.2 & - & - \\
\hline Isopropyl myristate $(\mathrm{g})$ & - & - & - & - & - & 2.2 & - \\
\hline Cyclomethicone $(\mathrm{g})$ & 1.3 & 1.3 & 1.3 & 1.3 & 1.3 & 1.3 & 1.3 \\
\hline $\operatorname{EDTA}(\mathrm{g})^{(3)}$ & 0.000025 & 0.000025 & 0.000025 & 0.000025 & 0.000025 & 0.000025 & 0.000025 \\
\hline Distilled water $(\mathrm{g})$ & 0.1 & 0.1 & 0.1 & 0.1 & 0.1 & 0.1 & 0.1 \\
\hline Citric acid $(\mathrm{g})$ & 0.01 & 0.01 & 0.01 & 0.01 & 0.01 & 0.01 & 0.01 \\
\hline $\mathrm{BHT}(\mathrm{g})^{(4)}$ & 0.01 & 0.01 & 0.01 & 0.01 & 0.01 & 0.01 & 0.01 \\
\hline Ethanol (g) & 6.82 & 5.38 & 5.38 & 5.38 & 5.38 & 5.38 & 5.38 \\
\hline Total $(\mathrm{g})$ & 10.0 & 10.0 & 10.0 & 10.0 & 10.0 & 10.0 & 10.0 \\
\hline \multicolumn{8}{|l|}{ Physicochemical characteristics } \\
\hline Appearance & Transparent & Transparent & Transparent & Transparent & Transparent & Transparent & Transparen \\
\hline Absorption/evaporation time ${ }^{(5)}$ & $13.7 \pm 0.5$ & $60.0 \pm 4.1$ & $75.0 \pm 12.2$ & $70.0 \pm 4.1$ & $118.3 \pm 8.5$ & $93.3 \pm 2.4$ & $45.0 \pm 2.4$ \\
\hline
\end{tabular}

(1) Propylene glycol monolaurate; ${ }^{(2)}$ Propylene glycol dicaprylocaprate; ${ }^{(3)}$ Ethylenediaminetetraacetic acid; ${ }^{(4)}$ Butylated hydroxytoluene; ${ }^{(5)}$ Data represent mean \pm standard deviation $(n=3)$. 
Table 2. Compositions and physicochemical characteristics of efinaconazole (EFN)-loaded hydroalcoholic solutions (HSs) with different hydrophilic permeation enhancers, along with Labrafac PG ${ }^{(1)}$ as a lipophilic enhancer.

\begin{tabular}{|c|c|c|c|c|}
\hline & LH-HS1 & LH-HS2 & LH-HS3 & LH-HS4 \\
\hline \multicolumn{5}{|c|}{ Compositions } \\
\hline $\mathrm{EFN}(\mathrm{g})$ & 1.0 & 1.0 & 1.0 & 1.0 \\
\hline Labrafac PG (g) & 1.5 & 1.5 & 1.5 & 1.5 \\
\hline SLS $(g)$ & 0.3 & - & - & - \\
\hline $\operatorname{DEPC}(\mathrm{g})^{(2)}$ & - & 0.3 & - & - \\
\hline $\mathrm{HP}-\beta-\mathrm{CD}(\mathrm{g})$ & - & - & 0.3 & 0.6 \\
\hline EDTA $(\mathrm{g})$ & 0.000025 & 0.000025 & 0.000025 & 0.000025 \\
\hline Distilled water (g) & 1.2 & 1.2 & 1.2 & 1.2 \\
\hline Citric acid (g) & 0.01 & 0.01 & 0.01 & 0.01 \\
\hline BHT $(\mathrm{g})$ & 0.01 & 0.01 & 0.01 & 0.01 \\
\hline Ethanol (g) & 5.78 & 5.78 & 5.78 & 5.48 \\
\hline Total $(\mathrm{g})$ & 10.0 & 10.0 & 10.0 & 10.0 \\
\hline \multicolumn{5}{|c|}{ Physicochemical characteristics } \\
\hline Appearance & Transparent & Transparent & Transparent & Transparent \\
\hline $\mathrm{pH}^{(3)}$ & $6.7 \pm 0.0$ & $5.2 \pm 0.0$ & $5.2 \pm 0.1$ & $5.2 \pm 0.1$ \\
\hline Absorption/evaporation time ${ }^{(3)}$ & $46.0 \pm 2.9$ & $54.0 \pm 2.9$ & $75.0 \pm 4.1$ & $70.0 \pm 4.1$ \\
\hline
\end{tabular}

Table 3. Compositions and physicochemical characteristics of efinaconazole (EFN)-loaded oil solutions (OSs) prepared with different oily vehicles.

\begin{tabular}{|c|c|c|c|}
\hline & OS1 & OS2 & OS3 \\
\hline \multicolumn{4}{|c|}{ Compositions } \\
\hline EFN $(g)$ & 1.0 & 1.0 & 1.0 \\
\hline Labrafac PG (g) & 8.0 & - & - \\
\hline Peppermint oil (g) & - & 8.0 & - \\
\hline Almond oil (g) & - & - & 8.0 \\
\hline Distilled water (g) & 0.01 & 0.01 & 0.01 \\
\hline Ethanol $(\mathrm{g})$ & 0.89 & 0.89 & 0.89 \\
\hline Total (g) & 10.0 & 10.0 & 10.0 \\
\hline \multicolumn{4}{|c|}{ Physicochemicalcharacteristics } \\
\hline $\begin{array}{c}\text { Appearance } \\
\mathrm{pH}^{(1)}\end{array}$ & $\begin{array}{c}\text { Transparent } \\
9.0 \pm 0.0\end{array}$ & $\begin{array}{c}\text { Transparent } \\
6.0 \pm 0.0\end{array}$ & $\begin{array}{c}\text { Transparent } \\
6.2 \pm 0.0\end{array}$ \\
\hline Absorption/evaporation time ${ }^{(1)}$ & $71.0 \pm 2.9$ & $27.3 \pm 2.1$ & $176.7 \pm 4.7$ \\
\hline
\end{tabular}

(1) Data represent mean \pm standard deviation $(n=3)$.

\section{Results}

\subsection{Effect of Lipophilic Penetration Enhancer on Transungual EFN Delivery}

In the present study, topical preparations containing different penetration enhancers were formulated to facilitate toenail delivery of EFN, and permeation profiles through the bovine hoof slice were evaluated in a Franz diffusion cell model. First, ethanol-based HS formulations containing different L-HSs were assessed for EFN delivery (Table 1). Volatile vehicles account for more than $50 \%$ of the total weight of preparations, not only to provide high drug loading $(10 \% w / w)$ with excellent solubilizing capacity but also to promote drug diffusion and/or penetration into nail plate by increasing concentration gradient after vaporization. As lipophilic absorption enhancers, several water-immiscible oily excipients, such as Lauroglycol 90, Labrafac PG, medium-chain triglyceride, isopropyl myristate, and isopropyl palmitate, were employed. Saner et al. (2014) reported that these lipophilic ingredients altered the microstructure of the nail plate by interacting with its lipid components, promoting drug penetration and increasing the efficacy of topical therapies [16]. Cyclomethicone, an oily ingredient, was commonly included in all L-HSs to ameliorate wetting and spreading of each formula onto the toenail. This oily ingredient has 
proven to effectively improve the spreading efficiency of topical preparations, primarily by lowering the surface tension between the nail plate and HS [12,13]. To prevent color changes in EFN-loaded topical preparations by oxidation reaction [13], antioxidants, including BHT and EDTA, were included in all preparations.

All L-HS preparations were transparent or pale yellow, with no drug precipitation. The drug content in all L-HS preparations was determined to be between $98 \%$ and $105 \%$, with no degradation during the preparation procedure (data not shown). After topical application of a drop of HS base onto the hoof slice, it was rapidly evaporated and/or absorbed into the nail within 14 min (Table 1). On the other hand, the incorporation of oily absorption enhancers markedly lengthened the complete absorption/evaporation time of L-HSs, displaying an absorption/evaporation time ranging from 45.0 to $118.3 \mathrm{~min}$. Despite the rapid vanishing of the organic solvent, non-volatile ingredients, including oily absorption enhancers, remained onto the hoof membrane and were slowly absorbed.

The in vitro permeation profile of EFN through bovine hoof slices after topical application of L-HSs is presented in Figure 2. To guarantee sink conditions during the in vitro permeation study, minimal amount of SLS, an anionic surfactant, was added to the receptor medium $(0.2 \% w / v)$. Although sink condition may not occur in vivo, due to the low interstitial fluid volume and to its low renovation rate of nail plate, it was required to compare permeation-enhancing capacity of each formulation more distinctly. In our preliminary test, SLS was effective in increasing the solubility of the sparingly soluble antifungal agent by forming micellar structures in aqueous media above the critical micellar concentration. The solubility of EFN in $0.2 \%$ SLS-containing PBS solution was $2.1 \mathrm{mg} / \mathrm{mL}$, whereas the drug solubility in PBS was approximately $0.02 \mathrm{mg} / \mathrm{mL}$ (data not shown). After topical application of HS base or L-HSs, drug molecules penetrated the hoof slice, with no marked lag time. Subsequently, the extent of EFN permeated steadily increased for $20 \mathrm{~h}$ in all HSs under sink conditions.

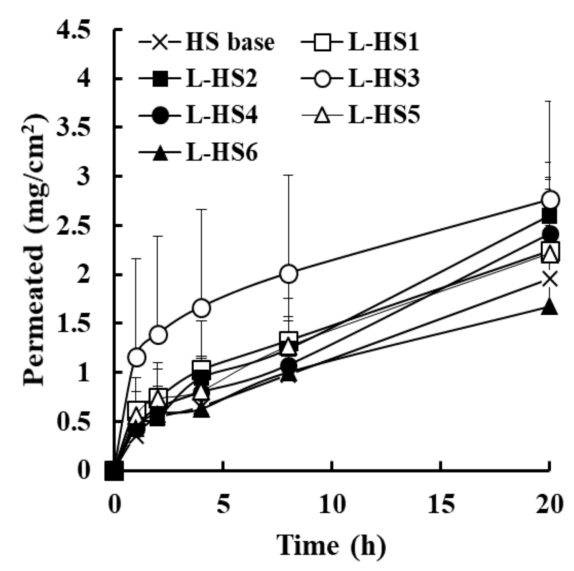

Figure 2. In vitro permeation profile of efinaconazole through the bovine hoof from L-hydroalcoholic solutions (HSs) with different lipophilic enhancers in the Franz diffusion cell model. Data represent mean \pm standard deviation $(n=4)$.

The overall amount of EFN permeated was higher in L-HS formulations, including L-HS3 (Labrafac PG, flux value of $138.1 \mu \mathrm{g} \cdot \mathrm{cm}^{-2} \cdot \mathrm{h}^{-1}$ ), L-HS2 (Lauroglycol 90, $129.9 \mu \mathrm{g} \cdot \mathrm{cm}^{-2} \cdot \mathrm{h}^{-1}$ ), L-HS4 (medium-chain triglyceride, $120.8 \mu \mathrm{g} \cdot \mathrm{cm}^{-2} \cdot \mathrm{h}^{-1}$ ), and L-HS1 (marketed formula, $\left.112.0 \mu \mathrm{g} \cdot \mathrm{cm}^{-2} \cdot \mathrm{h}^{-1}\right)$, compared to HS base $\left(97.6 \mu \mathrm{g} \cdot \mathrm{cm}^{-2} \cdot \mathrm{h}^{-1}\right)$; the amount of EFN permeation after topical application of L-HSs was over 41\% (L-HS3), 33\% (L-HS2), 24\% (L-HS4), and 13\% (L-HS5) higher than that of the HS base after $20 \mathrm{~h}$, respectively (Table 4). In particular, L-HS3 containing Labrafac PG as a lipophilic enhancer exhibited the highest permeability profile over the experimental period, showing $36 \%$ higher permeation than the commercialized composition (L-HS1) after $20 \mathrm{~h}$. Labrafac PG is an oily ingredient with hydrophilic-lipophilic balance (HLB) value of 2.0, which has been employed as an oil vehicle in topical formulations as an effective solubilizer. In fact, the oily ingredient 
showed high solubility for EFN (over $200 \mathrm{mg} / \mathrm{mL}$, data not shown). This high solubilizing capacity enabled EFN to maintain the dissolved state even after ethanol evaporation, providing an opportunity for continuous drug penetration. Haque et al. (2017) reported that considerable quantities of Labrafac PG were upheld in the skin tissue after topical application, which was helpful in maintaining water-insoluble drug in dissolved state in the relevant layer [21]. Salimi et al. (2016) revealed that Labrafac PG drastically diminished the skin resistance to drug penetration by obstructing lipid packing in the layer [22]. Taken together, Labrafac PG was included in HS formula as lipophilic enhancer.

Table 4. Flux and accumulated amount of efinaconazole (EFN) permeated through the bovine hoof for $20 \mathrm{~h}$ after the topical application of hydroalcoholic solutions (HSs) or oil solutions (OSs) in Franz diffusion cell model.

\begin{tabular}{ccc}
\hline Formulas & Flux $\left(\boldsymbol{\mu g} \cdot \mathbf{c m}^{-\mathbf{2}} \cdot \mathbf{h}^{-\mathbf{1}}\right)$ & Permeated $\mathbf{( \% )}$ \\
\hline HL base & $97.6 \pm 27.5$ & $18.2 \pm 5.1$ \\
L-HS1 & $112.0 \pm 45.0$ & $20.9 \pm 8.4$ \\
L-HS2 & $129.9 \pm 18.6$ & $24.3 \pm 3.5$ \\
L-HS3 & $138.1 \pm 35.0$ & $25.8 \pm 6.5$ \\
L-HS4 & $120.8 \pm 22.8$ & $22.6 \pm 4.2$ \\
L-HS5 & $110.5 \pm 38.9$ & $20.6 \pm 7.3$ \\
L-HS6 & $83.9 \pm 47.6$ & $15.7 \pm 8.9$ \\
LH-HS1 & $115.0 \pm 5.8$ & $21.4 \pm 2.2$ \\
LH-HS2 & $81.8 \pm 6.67$ & $15.3 \pm 1.8$ \\
LH-HS3 & $161.0 \pm 8.6^{*, * *}$ & $30.3 \pm 2.6 *, * *$ \\
LH-HS4 & $200.2 \pm 8.9 * * *$ & $37.4 \pm 3.5 * * *$ \\
OS1 & $93.0 \pm 1.5$ & $17.4 \pm 0.3$ \\
OS2 & $79.5 \pm 38.5$ & $14.8 \pm 7.2$ \\
OS3 & $71.0 \pm 39.0$ & $13.3 \pm 7.3$ \\
\hline
\end{tabular}

Data represent mean \pm standard deviation $(n=3-4) .{ }^{*} p<0.05$ versus HS-base; ${ }^{* *} p<0.05$ versus marketed composition (L-HS1).

\subsection{Combination of Hydrophilic Enhancer with Lipophilic Enhancer for Transungual EFN Delivery}

LH-HS formulas containing hydrophilic enhancers (SLS, DEPC, and HP- $\beta$-CD), along with Labrafac PG as a lipophilic enhancer, were further established, and their physicochemical properties and transungual permeation profiles were evaluated (Table 4). As hydrophilic absorption enhancers, several organic and/or inorganic substances have been attempted, such as SLS, HP- $\beta-C D$, phosphatidyl choline, urea, pantothenic acid, ascorbic acid, polyethylene glycol 300, potassium phosphate, and N-acetylcysteine $[20,23,24]$. Among them, pantothenic acid and ascorbic acid were excluded, as they were insoluble or rapidly degraded in HS preparations, respectively. Thiols, including $\mathrm{N}$-acetylcysteine, were not employed, as they might cause irreversible damage to nail plates. In designing LH-HSs, the proportion of distilled water in topical solutions was increased to $5 \%(w / v)$ to solubilize water-soluble enhancers. The increased water content in HS might be beneficial for ungual delivery, as the content of water in the nail plate is $10-30 \%$ and as the supplement of aqueous vehicle is important for swelling, elasticity, and flexibility of the nail structure [25]. In contrast, cyclomethicone, the wetting agent, was excluded from the LH-HSs, as this oily ingredient was phase-separated, as the content of hydrophilic substances was increased in preparations. All LH-HS formulations listed in Table 2 (LH-HS1 LH-HS4) were transparent or pale yellow, with no drug precipitation. The drug content in each formulation was set to $10 \%$, respectively. The time required for absorption and/or evaporation after topical application of LH-HSs (LH-HS1-LH-HS4) was determined to be between 46 and $75 \mathrm{~min}$ (Table 3), which is comparable to that of L-HS containing only Labrafac PG as a lipophilic enhancer (L-HS3).

The in vitro permeation profile of the antifungal agent through the hoof slice after topical application of LH-HSs is depicted in Figure 3. The permeation pattern of LH-HSs was analogous with that of L-HSs, exhibiting prompt penetration upon topical application, 
followed by a gradual increase for $20 \mathrm{~h}$. Among LH-HSs with different absorption enhancers, LH-HS3 containing HP- $\beta$-CD $(3 \% w / v)$ in combination with Labrafac PG showed higher flux values than LH-HS1 (SLS, $3 \% w / v$ ) or LH-HS2 (DEPC, $3 \% w / v)$ ); the flux values of EFN penetrated for $20 \mathrm{~h}$ after the application of LH-HS1, LH-HS2, and LH-HS3 were estimated to be $115.0,81.8$, and $161.0 \mu \mathrm{g} \cdot \mathrm{cm}^{-2} \cdot \mathrm{h}^{-1}$, respectively (Table 4). The permeation of EFN through the hoof slice was further increased as the proportion of HP- $\beta-C D$ increased $\left(6 \% w / v\right.$, LH-HS4), providing a flux value of $200.2 \mu \mathrm{g} \cdot \mathrm{cm}^{-2} \cdot \mathrm{h}^{-1}$. The extent of EFN permeation after treatment with LH-HS4 (HP- $\beta-\mathrm{CD}, 3 \% w / v)$ was even higher than that with L-HS1 (patented formula) or L-HS3 (Labrafac PG), exhibiting over $78 \%$ or $45 \%$ higher drug permeation across the hoof membrane, respectively (Table 4). The absorption improvement by HP- $\beta-\mathrm{CD}$ was consistent with the previous report where cyclodextrin derivatives markedly improved the hydration of nail plates and increased the solubility of terbinafine, facilitating drug permeation through the water-filled porous structure of hydrated nail plates [20]. From these findings, we concluded that the combined use of Labrafac PG and HP- $\beta-C D$ is advantageous in improving the absorption of EFN, with different permeation-facilitating mechanisms.

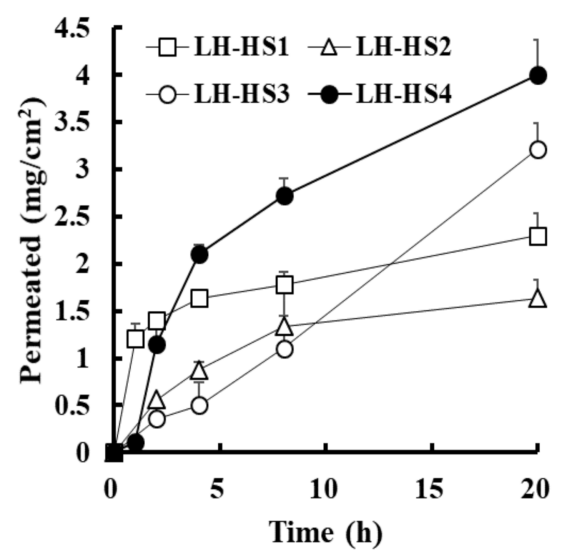

Figure 3. In vitro permeation profile of efinaconazole through the bovine hoof from LH-HS preparations prepared with different hydrophilic enhancers, along with Labrafac PG as a lipophilic enhancer in the Franz diffusion cell model. Data represent mean \pm standard deviation $(n=4)$.

\subsection{Effect of Oil Solution for Transungual EFN Delivery}

Different EFN-loaded OSs based on Labrafac PG (OS1), peppermint oil (OS2), and almond oil (OS3) were constructed and their physicochemical properties and in vitro permeation profile were further assessed (Table 4). Labrafac PG was confirmed to improve transungual delivery of EFN when included in ethanol-based L-HS2 formula. Essential oils, including peppermint oil or almond oil, are commonly employed in topical preparations for curing toenail fungus, as tocopherol included in essential oils possess antioxidant, antiinflammatory, and immune-boosting activities [26-28]. Moreover, oily vehicles consisting of benzyl alcohol, peppermint oil, turpentine, and mineral oil, effectively promoted the transungual delivery of ciclopirox [29]. Along with oily vehicles, ethanol and distilled water were included to improve the spreadability of the oily solution onto the nail plate. All OS preparations (OL1-OL3) were transparent or pale yellow, with a drug concentration of $10 \% w / v$. After topical application of OS2, volatile peppermint oil-based solution was completely absorbed and/or evaporated within $30 \mathrm{~min}$. On the other hand, it took about 70 or $176 \mathrm{~min}$ after the application of non-volatile oil-based OS1 or OS2, respectively (Table 4).

The in vitro permeation profile of EFN after topical application of OS formulations (OS1-OS3) is shown in Figure 4. OS formulations showed an overall lower permeation profile over the experimental period compared with L-HSs or LH-HSs, with no marked difference depending on the oily vehicle. The flux values of OS1, OS2, and OS3 were 93.0, 79.5, and $71.0 \mu \mathrm{g} \cdot \mathrm{cm}^{-2} \cdot \mathrm{h}^{-1}$, respectively (Table 4). The relatively poor wettability and/or spreadability of OSs might hinder the penetration of EFN-loaded oily vehicles 
into the hoof slice, showing a lower flux value than HSs, including LH-HS4 or even HS base. LH-HS4 containing both Labrafac PG and HP- $\beta$-CD as lipophilic and hydrophilic permeation enhancers, respectively, was chosen as the optimal preparation for the ungual delivery of EFN.

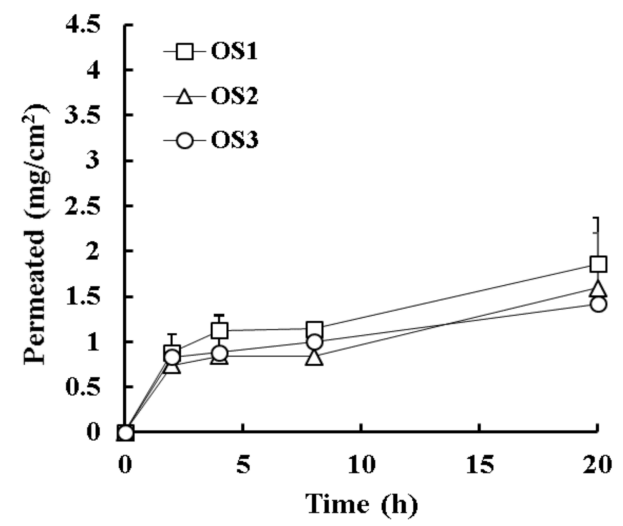

Figure 4. In vitro permeation profile of efinaconazole through the bovine hoof from oil solutions (OSs) prepared with different oily vehicles in the Franz diffusion cell model. Data represent mean \pm standard deviation $(n=3)$.

\subsection{Physicochemical Stability of Optimized EFN-Loaded LH-HS Preparation}

The physicochemical stability of the HL-HS4 formula was further evaluated under stress $\left(60^{\circ} \mathrm{C}\right.$ for six days) or ambient $\left(25^{\circ} \mathrm{C}\right.$ for 10 months) storage conditions (Table 5). The hydroalcoholic preparation of the antifungal agent has been reported to change from transparent to yellowish by oxidation reaction [12]. However, under both stress and ambient conditions, no changes in color and/or drug precipitation were observed in the HL-HS4 formulation. After 10 months storage at $25^{\circ} \mathrm{C}$, drug content in HL-HS4 was determined to $94.8 \%$, with no $\mathrm{pH}$ change in liquid preparation. Drug content in HL-HS4 has decreased by $2.5 \%$ for 10 months, compared to the initial drug content. Thus, the HL-HS4 formulation containing Labrafac PG and HP- $\beta-C D$ was assumed to be physicochemically stable, providing over $90 \%$ drug content over 24 months under ambient condition.

Table 5. Physicochemical stability of the optimized topical solution (LH-HS4) under stress $\left(60^{\circ} \mathrm{C}\right.$ for six days) and ambient condition $\left(25^{\circ} \mathrm{C}\right.$ for 10 months).

\begin{tabular}{|c|c|c|c|}
\hline & After Preparation & Under Stress Conditions & Under Ambient Conditions \\
\hline Appearance & Transparent & Transparent & Transparent \\
\hline $\mathrm{pH}^{(1)}$ & $5.2 \pm 0.1$ & $5.2 \pm 0.0$ & $5.3 \pm 0.01$ \\
\hline Drug content $(\%)$ & $97.3 \pm 1.8$ & $94.0 \pm 1.1$ & $94.8 \pm 0.0$ \\
\hline
\end{tabular}

(1) Data represent mean \pm standard deviation $(n=3)$.

\section{Materials and Methods}

\subsection{Materials}

EFN powder (purity $>99.9 \%$ ) was obtained from Cipla Limited (Mumbai, India). Myristyl lactate, diisopropyl adipate, HP- $\beta-C D$, SLS, peppermint oil, almond oil, BHT, ethanol, EDTA, sodium azide, phosphate-buffered saline (PBS) tablets, and citric acid were purchased from Sigma-Aldrich Chemical Co. (St. Louis, MO, USA). Labrafac PG, Lauroglycol 90, medium-chain triglyceride (MCT, Labrafac Lipophile WL1349), isopropyl myristate, and isopropyl palmitate were obtained from Gattefosse (Saint-Priest, France). Cyclomethicone and DEPC were acquired from Dow silicone Co. (Midland, MI, USA) and Lipoid (Newark, NJ, USA), respectively. 


\subsection{Preparation of EFN-Loaded Topical Solutions}

Different HS preparations containing EFN $(10 \% w / w)$ were prepared using a conventional procedure as described previously [23]. The compositions of the HS base and L-HS, and LH-HS prepared in our study are listed in Tables 1 and 2, respectively. First, EFN ( $1 \mathrm{~g})$ was added to ethanol (5.3-6.8 g) and stirred for $30 \mathrm{~min}$ to obtain a transparent solution. Then, lipophilic permeation enhancers (myristyl lactate, diisopropyl adipate, Labrafac PG, MCT, Lauroglycol 90, isopropyl myristate, and isopropyl palmitate, 1.5-2.2 g), cyclomethicone $(0-1.3 \mathrm{~g})$, and BHT $(0.01 \mathrm{~g})$ were added to the ethanol solution. Then, aqueous solution (0.1-1.2 g) containing hydrophilic enhancers (HP- $\beta-C D$, DEPC, and SLS), EDTA, citric acid, and BHT were added to the drug solution. The mixture was stirred for $10 \mathrm{~min}$ using a stirrer. The final weight of the topical solution was adjusted to $10 \mathrm{~g}$ by dropwise addition of ethanol.

EFN-loaded OSs with different oily vehicles were further prepared using a conventional procedure, as described previously (Table 3). EFN ( $1 \mathrm{~g})$ was dissolved in $8 \mathrm{~g}$ of oily vehicle (Labrafac PG, almond oil, and peppermint oil) by vigorous vortexing for $30 \mathrm{~min}$. To reduce the viscosity of the drug-loaded oil solution, $0.89 \mathrm{~g}$ of ethanol and $0.01 \mathrm{~g}$ of distilled water were added to the solution and stirred for $30 \mathrm{~min}$. The prepared formulations were kept in glass vials at room temperature.

\subsection{Physicochemical Characteristics of EFN-Loaded Topical Preparations}

The physicochemical properties of EFN-loaded topical solutions were characterized by appearance, drug content, $\mathrm{pH}$, and absorption/evaporation time into the bovine hoof membrane. After placing the sample in a glass vial, the transparency and the presence of drug precipitates and/or aggregates were visually observed. The acidity of each sample was determined using a $\mathrm{pH}$ meter (Mettler Toledo, Greifensee, Switzerland).

The drug content in each formula was determined using HPLC analysis previously reported, with slight modifications [30]. Each sample $(100 \mu \mathrm{L})$ was 1,000-fold diluted with acetonitrile (ACN) and injected into a Shimadzu HPLC system (Shimadzu, Kyoto, Japan) equipped with a pump (LC-20AD XR), autosampler (SIL-20AC XR), UV-VIS detector SPD-M20A), and system controller (CBM-20A). Chromatographic separation of EFN was achieved isocratically using a reverse-phase C18 column $(4.6 \mathrm{~mm} \mathrm{I.D.} \times 250 \mathrm{~mm}, 5 \mu \mathrm{m}$, Shiseido, Japan) with a mixture of ACN and distilled water $(8: 2 \mathrm{v} / \mathrm{v})$ as the mobile phase. The flow rate of the mobile phase was set to $1.0 \mathrm{~mL} / \mathrm{min}$. The temperature of the column oven (CTO-20A) was set to $30^{\circ} \mathrm{C}$. The eluent was monitored at $210 \mathrm{~nm}$ with a retention time of about $5 \mathrm{~min}$. The calibration curve for EFN was linear in the concentration range of $1-100 \mu \mathrm{g} / \mathrm{mL}\left(\mathrm{y}=36319 \mathrm{x}+21103, r^{2}=1.0\right.$, where $\mathrm{x}$ and $\mathrm{y}$ are the drug concentration $(\mu \mathrm{g} / \mathrm{mL})$ and peak area, respectively). The limit of detection (LOD) and the limit of quantitation (LOQ) values were calculated to 0.1 and $0.5 \mu \mathrm{g} / \mathrm{mL}$, respectively.

\subsection{Absorption/Evaporation Time of EFN-Loaded Topical Preparations}

To compare the absorption and/or evaporation rate of each formula, the absorption/evaporation time of each sample into bovine hoof slices was further evaluated. Before the experiment, bovine hoof tissues were carefully washed and hydrated in distilled water for $24 \mathrm{~h}$. The softened tissues were cut into thin slices using a microtome (RM2245 SemiAutomated Rotary Microtome, Leica, Germany). The thickness of the slices was measured using a micrometer (Mitutuyo, Guipúzcoa, Spain), and slices with similar thickness and no visible faults or fissures were chosen for the study. The thickness of the hoof slices was ranged from 0.20 to $0.25 \mathrm{~mm}$. A drop of sample (approximately $30 \mu \mathrm{L}$ ) was loaded onto a bovine hoof slice using a pipette, and the time required for complete absorption was determined by dry-to-touch in a shaking incubator maintained at $32{ }^{\circ} \mathrm{C}$.

\subsection{In Vitro Permeation Study of EFN-Loaded Topical Preparations}

The in vitro drug permeation profile through bovine hoof slices after topical application of EFN-loaded preparations was evaluated in the vertical Franz diffusion cell 
model [23,31,32]. On the day of the permeation experiment, the hoof slices immersed in PBS for $1 \mathrm{~h}$ were clamped between two Teflon cylindrical adapters (silicone, Vollmond, Seoul, Korea), providing an effective diffusional area of $0.28 \mathrm{~cm}^{2}$. Adapters with samples were clamped between the donor and receptor chambers of vertical Franz diffusion cells. The receptor compartment was filled with $12 \mathrm{~mL}$ of $10 \mathrm{mM}$ PBS (pH 7.4) containing $0.01 \%(w / v)$ sodium azide as a microbial growth inhibitor and $0.2 \%(w / v)$ SLS as solubility enhancer. Afterward, each formulation containing an equivalent amount of EFN (3 mg) was applied on the donor compartment. During the experiment, the receptor medium was stirred at $450 \mathrm{rpm}$ using a magnetic stirrer, and the temperature was kept at $32{ }^{\circ} \mathrm{C}$. At a predetermined time, $0.2 \mathrm{~mL}$ of receptor media was withdrawn using a syringe, and prewarmed fresh media were refurnished in the receptor compartment. The withdrawn samples were diluted with methanol and analyzed using HPLC. Flux value of each formulation was calculated by dividing the accumulative amount of EFN permeated at $20 \mathrm{~h}$ $\left(\mathrm{mg} / \mathrm{cm}^{2}\right)$ by the time $(20 \mathrm{~h})$. The permeation data were statistically analyzed by Student's $t$-test using SPSS software 17.0.

\subsection{Physicochemical Stability of EFN-Loaded Topical Preparation}

For selected topical preparation, the physicochemical stability was evaluated under stress $\left(60^{\circ} \mathrm{C}\right)$ and ambient conditions $\left(25^{\circ} \mathrm{C}\right)$. LH-HS4 kept in glass vials was stored at $60{ }^{\circ} \mathrm{C}$ for 6 days or at $25^{\circ} \mathrm{C}$ for 10 months. The withdrawn sample was evaluated by aspect of appearance (phase separation or drug precipitation), acidity, and drug content.

\section{Conclusions}

In this study, EFN-loaded HS preparations containing different lipophilic and/or hydrophilic absorption enhancers were formulated, and their permeation profiles were successfully evaluated using bovine hoof slices. The optimized HS formula combining lipophilic (Labrafac PG) with hydrophilic penetration enhancer (HP- $\beta-C D$ ) offered favorable permeation profile, providing over two-fold increased flux value compared with the HS base with no permeation enhancer. Moreover, the novel formula was physicochemically stable, with no changes in appearance, acidity, and drug content under stress or ambient conditions. Therefore, this novel HS can be a promising tool for the delivery of EFN in the treatment of toenail onychomycosis.

Author Contributions: Conceptualization, J.S.P., J.S.K., and M.J.K.; data curation, J.S.P., and M.J.H.; formal analysis, J.S.P., D.W.P., and E.A.K.; funding acquisition, M.J.K.; methodology, J.S.P., and J.S.K.; supervision, Y.S.C., S.W.J., and M.J.K.; writing-original draft, J.S.P.; writing-review and editing, J.S.K. and M.J.K. All authors have read and agreed to the published version of the manuscript.

Funding: This research was supported by Basic Science Research Program through the National Research Foundation of Korea (NRF) funded by the Ministry of Science, ICT and Future Planning (NRF-2019R1C1C1004211). This research has been done by the author(s) working at the Department of Pharmacy of Dankook University. Department of Pharmacy was supported by the ResearchFocused Department Promotion Project as a part of the University Innovation Support Program 2020 to Dankook University.

Institutional Review Board Statement: Not applicable.

Informed Consent Statement: Not applicable.

Data Availability Statement: The data that support the findings of this study are available from the corresponding author upon reasonable request.

Conflicts of Interest: The authors declare that there are no conflicts of interest.

Sample Availability: Samples of the compounds are available from the authors. 


\section{References}

1. de Berker, D. Nails and hair. Medicine 2009, 37, 286-290. [CrossRef]

2. Sigurgeirsson, B.; Steingrímsson, O. Risk factors associated with onychomycosis. J. Eur. Acad. Dermatol. Venereol. 2004, $18,48-51$. [CrossRef]

3. Siu, W.J.J.; Tatsumi, Y.; Senda, H.; Pillai, R.; Nakamura, T.; Sone, D.; Fothergill, A. Comparison of In Vitro ntifungal activities of efinaconazole and currently available antifungal agents against a variety of pathogenic fungi associated with onychomycosis. Antimicrob. Agents Chemother. 2013, 57, 1610-1616. [CrossRef]

4. Tatsumi, Y.; Nagashima, M.; Shibanushi, T.; Iwata, A.; Kangawa, Y.; Inui, F.; Siu, W.J.J.; Pillai, R.; Nishiyama, Y. Mechanism of action of efinaconazole, a novel triazole antifungal agent. Antimicrob. Agents Chemother. 2013, 57, 2405-2409. [CrossRef]

5. Sugiura, K.; Sugimoto, N.; Hosaka, S.; Katafuchi-Nagashima, M.; Arakawa, Y.; Tatsumi, Y.; Siu, W.J.; Pillai, R. The low keratin affinity of efinaconazole contributes to its nail penetration and fungicidal activity in topical onychomycosis treatment. Antimicrob. Agents Chemother. 2014, 58, 3837-3842. [CrossRef]

6. FDA Label of JUBLIA ${ }^{\circledR}$ (efinaconazole) Topical Solution. Available online: https://www.accessdata.fda.gov/drugsatfda_docs / label/2014/203567s000lbl.pdf (accessed on 21 October 2020).

7. Walters, K.A.; Abdalghafor, H.M.; Lane, M.E. The human nail—Barrier characterisation and permeation enhancement. Int. J. Pharm. 2012, 435, 10-21. [CrossRef] [PubMed]

8. Tiwary, A.K.; Sapra, B. High failure rate of transungal drug delivery: Need for new strategies. Ther. Deliv. 2017, 8, 239-242. [CrossRef]

9. Cutrín-Gómez, E.; Anguiano-Igea, S.; Delgado-Charro, M.B.; Gómez-Amoza, J.L.; Otero-Espinar, F.J. Effect of penetration enhancers on drug nail permeability from Cyclodextrin/Poloxamer-soluble polypseudorotaxane-based nail lacquers. Pharm. 2018, 10, 273. [CrossRef]

10. Dykyj, J.D. Anatomy of the nail. Clin. Poditr. Med. Sur. 1989, 6, 521-528. [PubMed]

11. Vikas, A.; Rashmin, P.; Mrunali, P.; Chavan, R.B.; Kaushik, T. Mechanistic insights of formulation approaches for the treatment of nail infection: Conventional and novel drug delivery approaches. AAPS PharmSciTech 2020, 21, 1-12. [CrossRef]

12. Bhatt, V.; Pillai, R. Efinaconazole topical solution, $10 \%$ : Formulation development program of a new topical treatment of toenail onychomycosis. J. Pharm. Sci. 2015, 104, 2177-2182. [CrossRef]

13. Lee, B.C.; Pangeni, R.; Na, J.; Koo, K.-T.; Park, J.W. Preparation and in vivo evaluation of a highly skin- and nail-permeable efinaconazole topical formulation for enhanced treatment of onychomycosis. Drug Deliv. 2019, 26, 1167-1177. [CrossRef]

14. Brown, M.; Khengar, R.; Turner, R.; Forbes, B.; Traynor, M.; Evans, C.; Jones, S. Overcoming the nail barrier: A systematic investigation of ungual chemical penetration enhancement. Int. J. Pharm. 2009, 370, 61-67. [CrossRef] [PubMed]

15. Dutet, J.; Delgado-Charro, M.B. In vivo transungual iontophoresis: Effect of DC current application on ionic transport and on transonychial water loss. J. Control. Release 2009, 140, 117-125. [CrossRef] [PubMed]

16. Saner, M.V.; Kulkarni, A.D.; Pardeshi, C.V. Insights into drug delivery across the nail plate barrier. J. Drug Target. 2014, 22, 769-789. [CrossRef]

17. Özdemir, G.; Sezgin, Ö.E. Keratin-rhamnolipids and keratin-sodium dodecyl sulfate interactions at the air/water interface. Colloids Surf. B Biointerfaces 2006, 52, 1-7. [CrossRef] [PubMed]

18. Nair, A.B.; Sammeta, S.M.; Vaka, S.R.K.; Narasimha Murthy, S. A study on the effect of inorganic salts in transungual drug delivery of terbinafine. J. Pharm. Pharmacol. 2009, 61, 431-437. [CrossRef]

19. Hui, X.; Wester, R.C.; Maibach, H.I. Nail penetration. In Textbook of Cosmetic Dermatology; Informa UK Limited: London, UK, 2010; pp. 63-72.

20. Chouhan, P.; Saini, T.R. Hydroxypropyl- $\beta$-cyclodextrin: A Novel Transungual Permeation Enhancer for Development of Topical Drug Delivery System for Onychomycosis. J. Drug Deliv. 2014, 2014, 1-7. [CrossRef]

21. Haque, T.; Rahman, K.M.; Thurston, D.E.; Hadgraft, J.; Lane, M.E. Topical delivery of anthramycin I. Influence of neat solvents. Eur. J. Pharm. Sci. 2017, 104, 188-195. [CrossRef]

22. Salimi, A.; Hedayatipour, N.; Moghimipour, E. The effect of various vehicles on the naproxen permeability through rat skin: A mechanistic study by DSC and FT-IR Techniques. Adv. Pharm. Bull. 2016, 6, 9-16. [CrossRef]

23. Cutrín-Gómez, E.; Anguiano-Igea, S.; Delgado-Charro, M.B.; Gómez-Amoza, J.L.; Otero-Espinar, F.J. Effect on nail structure and transungual permeability of the ethanol and poloxamer ratio from cyclodextrin-soluble polypseudorotaxanes based nail lacquer. Pharm. 2018, 10, 156. [CrossRef]

24. Angelo, T.; Borgheti-Cardoso, L.N.; Gelfuso, G.M.; Taveira, S.F.; Gratieri, T. Chemical and physical strategies in onychomycosis topical treatment: A review. Med. Mycol. 2016, 55, 461-475. [CrossRef]

25. Finlay, A.Y.; Frost, P.; Keith, A.D.; Snipes, W. An assessment of factors influencing flexibility of human fingernails. Br. J. Dermatol. 1980, 103, 357-365. [CrossRef]

26. Miguel, M.G. Antioxidant and anti-inflammatory activities of essential oils: A short review. Molecules 2010, 15, 9252-9287. [CrossRef]

27. Alessandrini, A.; Starace, M.; Bruni, F.; Piraccini, B.M. An open study to evaluate effectiveness and tolerability of a nail oil composed of vitamin E and essential oils in mild to moderate distal subungual onychomycosis. Ski. Appendage Disord. 2019, 6, 14-18. [CrossRef] 
28. Flores, F.C.; De Lima, J.A.; Ribeiro, R.F.; Alves, S.H.; Rolim, C.M.B.; Beck, R.C.R.; Da Silva, C.B. Antifungal activity of nanocapsule suspensions containing tea tree oil on the growth of trichophyton rubrum. Mycopathology 2013, 175, 281-286. [CrossRef]

29. Hafeez, F.; Hui, X.; Selner, M.; Rosenthal, B.; Maibach, H. Ciclopirox delivery into the human nail plate using novel lipid diffusion enhancers. Drug Dev. Ind. Pharm. 2013, 40, 838-844. [CrossRef] [PubMed]

30. Vikas, A.; Rashmin, P.; Mrunali, P.; Sandip, M.; Kaushik, T. RP-HPLC method for quantitative estimation of Efinaconazole in topical microemulsion and microemulsion-based-gel formulations and in presence of its degradation products. Microchem. J. 2020, 155, 104753. [CrossRef]

31. Nogueiras-Nieto, L.; Gomez-Amoza, J.L.; Delgado-Charro, M.B.; Otero-Espinar, F. Hydration and N-acetyl-1-cysteine alter the microstructure of human nail and bovine hoof: Implications for drug delivery. J. Control. Release 2011, 156, 337-344. [CrossRef]

32. Walter, R.; Edward, S.; Murray, J. Skin temperature response of normal human subjects to various conditions. Circulation 1952, 6 , 862-867. [CrossRef] 